\title{
Correction: Hokynar, K. et al. Chlamydia-Like Organisms (CLOs) in Finnish Ixodes ricinus Ticks and Human Skin. Microorganisms 2016, 4, 28
}

\author{
Kati Hokynar ${ }^{1, *}$, Jani J. Sormunen ${ }^{2}{ }^{\oplus}$, Eero J. Vesterinen ${ }^{2,3}$, Esa K. Partio ${ }^{4}$, Thomas Lilley ${ }^{5}$, \\ Veera Timonen ${ }^{1}{ }^{\mathbb{D}}$, Jaana Panelius ${ }^{6}$, Annamari Ranki ${ }^{6}$ and Mirja Puolakkainen ${ }^{1}(\mathbb{D}$ \\ 1 Department of Virology, Hartman Institute, University of Helsinki, 00014 Helsinki, Finland; \\ mirja.puolakkainen@helsinki.fi \\ 2 Department of Biology, University of Turku, 20014 Turku, Finland; jjtsor@utu.fi (J.J.S.); ejvest@utu.fi (E.J.V.) \\ 3 Department of Agricultural Sciences, University of Helsinki, 00014 Helsinki, Finland \\ 4 Medical Center Söder, 01150 Söderkulla, Finland; ejvest@utu.fi \\ 5 Biology Department, Bucknell University, Lewisburg, PA 17837, USA; tmlill@utu.fi \\ 6 Department of Dermatology and Allergology, University of Helsinki and Helsinki University Central \\ Hospital, 00250 Helsinki, Finland; jaana.panelius@hus.fi (J.P.); annamari.ranki@hus.fi (A.R.) \\ * Correspondence: kati.hokynar@Helsinki.fi
}

Received: 11 February 2019; Accepted: 18 February 2019; Published: 22 February 2019

The authors wish to make the following modification to this paper [1]. The forward primer sequence in page 3 should read: (panCh-Fwd [5'-ccgccaacactgggact- $\left.3^{\prime}\right]$.

We want to emphasize that this is a typographical error: the sequence of the forward primer used in this study was as indicated in the original publication (Lienard et al. 2011) [1] and in the corrected text.

The manuscript will be updated, and the original will remain online on the article webpage, with a reference to this Correction.

\section{References}

1. Hokynar, K.; Sormunen, J.J.; Vesterinen, E.J.; Partio, E.K.; Lilley, T.; Timonen, V.; Panelius, J.; Ranki, A.; Puolakkainen, M. Chlamydia-Like Organisms (CLOs) in Finnish Ixodes ricinus Ticks and Human Skin. Microorganisms 2016, 4, 28. [CrossRef] [PubMed]

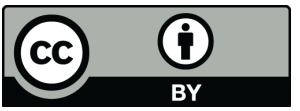

(C) 2019 by the authors. Licensee MDPI, Basel, Switzerland. This article is an open access article distributed under the terms and conditions of the Creative Commons Attribution (CC BY) license (http:/ / creativecommons.org/licenses/by/4.0/). 